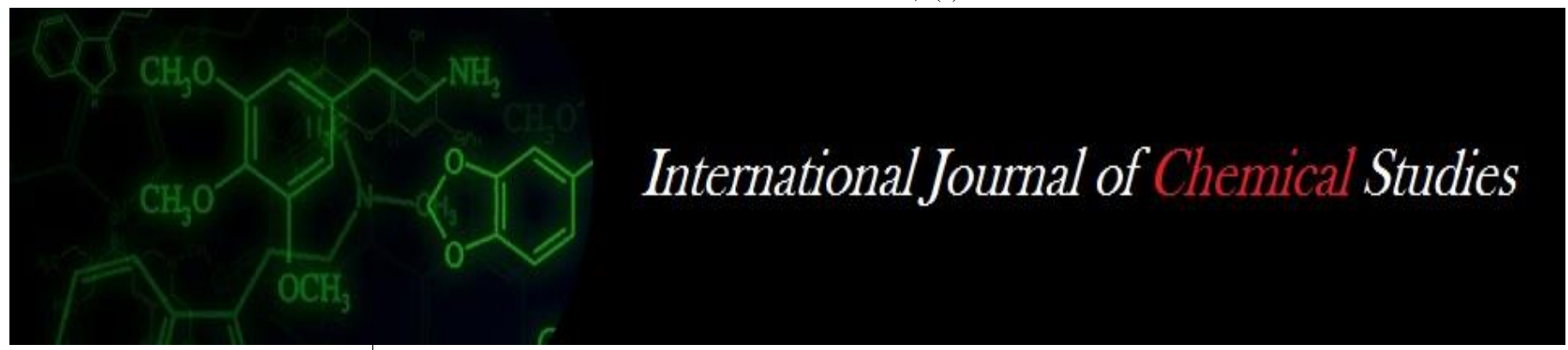

P-ISSN: 2349-8528

E-ISSN: 2321-4902

www.chemijournal.com

IJCS 2020; 8(4): 1066-1069

(C) 2020 IJCS

Received: 13-05-2020

Accepted: 17-06-2020

Rattan Singh

Centre of Food Science and

Technology, CCS Haryana

Agricultural University, Hisar,

Haryana, India

\section{Rakesh Gehlot}

Centre of Food Science and

Technology, CCS Haryana

Agricultural University, Hisar,

Haryana, India

\section{Rekha}

Centre of Food Science and

Technology, CCS Haryana

Agricultural University, Hisar,

Haryana, India

\section{Ritu Sindhu}

Centre of Food Science and

Technology, CCS Haryana

Agricultural University, Hisar,

Haryana, India

\section{Sandeep Kumar}

Centre of Food Science and

Technology, CCS Haryana

Agricultural University, Hisar,

Haryana, India
Corresponding Author:

Rattan Singh

Centre of Food Science and

Technology, CCS Haryana

Agricultural University, Hisar,

Haryana, India

\section{Changes in chemical constituents of banana-guava cheese during storage}

\author{
Rattan Singh, Rakesh Gehlot, Rekha, Ritu Sindhu and Sandeep Kumar
}

DOI: https://doi.org/10.22271/chemi.2020.v8.i4h.9745

\begin{abstract}
Banana-Guava cheese was developed by replacing $25 \%$ sugar with stevia and jaggery. The cheese variants were evaluated for changes in chemical parameters at monthly interval for three months storage period. Total sugars, reducing sugars, acidity, non-enzymatic browning and peroxide value increased significantly, while ascorbic acid, total carotenoids, total phenols and water activity decreased significantly in banana-guava cheese with the advancement in three months storage period.
\end{abstract}

Keywords: Banana, guava, blends, cheese, chemical, parameter, storage

\section{Introduction}

Confectionery items are considered as broad segment of our market and most of these products are prepared by flavour and concentrate of fruits; not directly from pulp that can harm our health, but fruit cheese is the product prepared from pulp/puree of sound ripe fruits, whether fresh, frozen or previously preserved, by cooking with salt and nutritive sweeteners to obtain a thick consistency so that it can set on cooling. Cheese is neither too soft nor too hard to chew. It may be prepared from any of the suitable fruits, singly or in combinations, hence, it contains the original fruits' flavour.

Health awareness around the globe is increasing leading to demand for low calorie food products in addition to food containing functional ingredients. Sweeteners help in controlling body weight and insulin levels as these add practically no or low calories to your diet. Sweeteners from plant sources are called as natural sweeteners like stevia. Stevia (Stevia rebaudiana) is a small shrub, also known as sweet leaf or sugar leaf. It is a member of Compositae family (Brandle \& Telmer, 2007) ${ }^{[6]}$. Stevia leaves contain complex mixture of diterpene glycosides, including stevioside, rebaudiosides, steviolbioside and dulcoside A (Kennelly, 2002; Starrat et al., 2002) ${ }^{[9,21]}$, which are responsible for its sweetness. Steviosides are 250 to 300 times sweeter than sugar.

Jaggery, also known as gur, is a natural product made by concentrating sugarcane juice. It contains important minerals like calcium (40-100 mg), magnesium (70-90 mg), potassium (1056 mg), phosphorus (20-90 mg), sodium (19-30 mg), iron (10-13 mg), manganese (0.2-0.5 $\mathrm{mg}$ ), zinc (0.2- $0.4 \mathrm{mg})$, copper (0.1-0.9 mg) and chloride $(5.3 \mathrm{mg})$ per $100 \mathrm{~g}$ of jaggery (Nath, $2015)^{[13]}$. It is digested slower than sugar and provides energy for a longer time. It is also a very good cleansing agent and safe for our body.

Banana (Musa paradisiaca L.) belongs to family Musaceae and is one of the most widely cultivated fruits in tropical countries. Pulp of ripe banana fruit contains $18 \%$ sugar and is also rich in vitamin A and B (Aurore et al., 2009) ${ }^{[5]}$. According to Adamu et al. (2017) ${ }^{[1]}$, it contains moisture $(58.24 \mathrm{~g} / 100 \mathrm{~g})$, carbohydrates $(30.33 \mathrm{~g} / 100 \mathrm{~g})$, protein $(3.5 \mathrm{~g} / 100 \mathrm{~g})$, fat $(1.30 \mathrm{~g} / 100 \mathrm{~g})$, crude fibre $(3.53 \mathrm{~g} / 100 \mathrm{~g})$ and ash $(3.10 \mathrm{~g} / 100 \mathrm{~g})$. Ripe banana has antioxidant properties and is rich in carotenoids $(735 \mathrm{mg} / 100 \mathrm{~g})$, ascorbic acid $(12.7 \mathrm{mg} / 100 \mathrm{~g})$, citric acid and malic acid (Kumar et al., 2012) ${ }^{[11]}$. The quality of fresh banana decreases drastically after harvesting as a result of deterioration in fruit colour, flavour and texture. Hence, it has always been considered a problematic fruit. Exploring possibilities of converting banana into value added products is one of the ways of solving this problem. Various products like chips, readyto-serve drink, flour, jam, confections, dehydrated slices, pickles and purees can be prepared from this fruit. 
Guava (Psidium guajava L.) belongs to family Myrtaceae. The fruit has about $83 \%$ moisture and is an excellent source of ascorbic acid. It contains about four times more the amount of vitamin $\mathrm{C}$ as present in orange. The fruits are available in excess quantity during certain period of the year and are spoilt in large quantities due to absence of post-harvest facilities and knowhow for proper handling, distribution, marketing and storage. Therefore, it is needed to emphasize that guava fruits should be processed into acceptable products so that the growers could get a remunerative price and consumers of all over the World could get an opportunity to enjoy guava fruits in the form of its processed products such as jam, jelly, toffee, nectar, squash, vinegar, canned guava, etc. Keeping the above all aspects in view, the present research work was planned to develop banana-guava cheese variants by replacing sugar with stevia and jaggery and to evaluate changes in chemical constituents of the products during three months storage.

\section{Materials and Methods}

The present investigation was carried out in CFST, CCSHAU, Hisar during 2017-18. Stevia powder was procured from Green Valley Stevia, Nawanshahr, Punjab. Jaggery, banana and guava fruits were procured from local market, Hisar. Banana and guava pulp were collected as per standard procedure (Fig. 1 and 2).

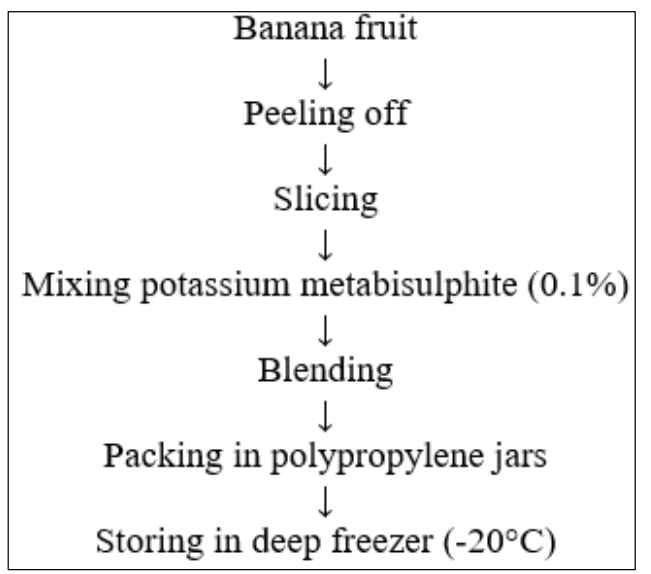

Fig 1: Flow sheet for collection and storage of banana pulp

\begin{tabular}{|c|}
\hline Ripe guava fruits \\
$\downarrow$ \\
Washing and cutting into thin slice \\
$\downarrow$ \\
Passing through pulper \\
$\downarrow$ \\
Guava pulp \\
$\downarrow$ \\
Mixing sodium benzoate \\
(1g/kg pulp) \\
$\downarrow$ \\
Packing in polypropylene jars \\
$\downarrow$ \\
Storing in deep freezer $\left(-20^{\circ} \mathrm{C}\right)$ \\
\hline
\end{tabular}

Fig 2: Flow sheet for collection and storage of guava pulp

Value added banana-guava cheese was prepared using one $\mathrm{kg}$ blended pulp (40 Banana:60 Guava), $860 \mathrm{~g}$ sugar, $4 \mathrm{~g}$ citric acid, $70 \mathrm{~g}$ butter, $5 \mathrm{~g}$ salt and $20 \mathrm{~g}$ pectin (Fig. 3). The mixture of pulp, sugar, sugar+stevia (replacing $25 \%$ of sugar with stevia), sugar+jaggery (replacing $25 \%$ of sugar with jaggery), butter and citric acid was cooked with constant stirring with a ladle to obtain desired consistency. Pectin was dissolved in lukewarm water and mixed with the cooking mass. Finally, salt was mixed with the cooked mass when it started leaving sides of the pan. End point was judged by sheet test and total soluble solids $(68 \%)$ were measured using hand refractometer (58-92\%). The product was finally spread on trays smeared with butter and left for cooling and setting. After setting, cheese was cut into equal size pieces, wrapped in butter paper and packed in LDPE bags. The product was evaluated for changes in chemical parameters at monthly interval during three months storage period.

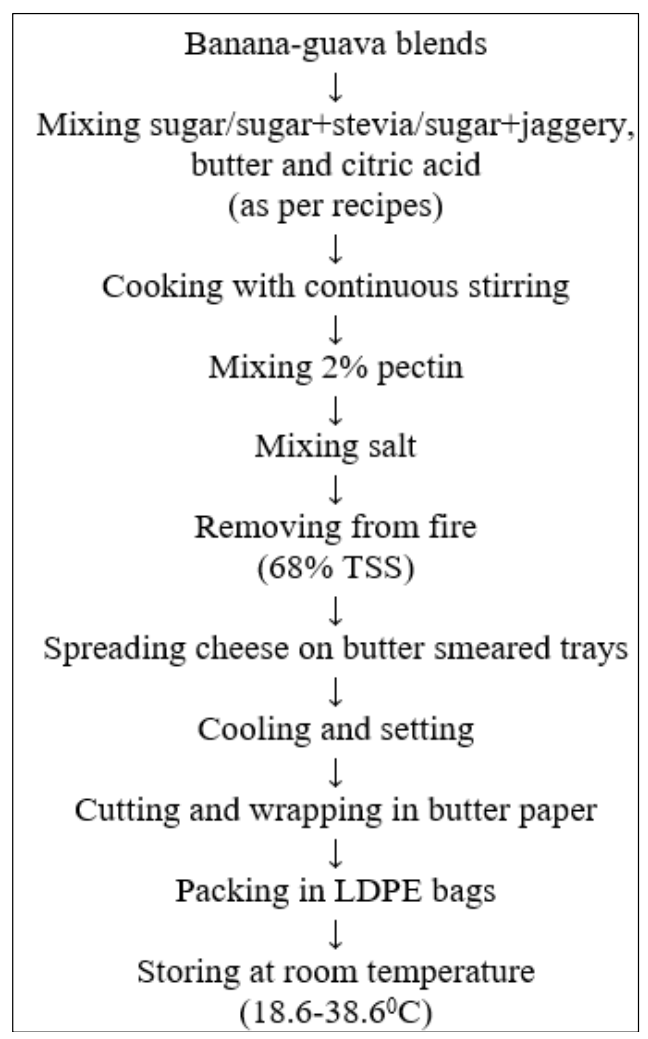

Fig 3: Flow sheet for preparation of banana-guava cheese

Total and reducing sugars in banana-guava cheese were estimated by titration method as suggested by Hulme \& Narain (1931) ${ }^{[8]}$. Acidity, ascorbic acid and non-enzymatic browning were determined according to methods described by Ranganna (2014) ${ }^{[16]}$. Total carotenoids were analyzed by Rodriguez-Amaya method (2004) ${ }^{[18]}$, while total phenols were estimated by the method suggested by Amorium et al. (1997) ${ }^{[2]}$. Peroxide value in banana-guava cheese was determined by the standard method of AOAC (2005) ${ }^{[3]}$. The water activity in cheese samples was assessed with the help of water activity meter (Rotronic Hydro Lab.).

\section{Results and Discussion}

The perusal of data presented in Table 1 show an increasing trend in total and reducing sugars of banana-guava cheese variants during three months storage. The increase in total and reducing sugars of the products during storage might be due to hydrolysis of some carbohydrates like pectin, cellulose, starch, etc. and due to conversion of non-reducing to reducing sugars. Similar increase in total and reducing sugars of cheese during storage has also been reported by Singh et al. (2017) [20] in pineapple and apple blended cheese, and Mehto \& Mehto (2017) ${ }^{[12]}$ in guava cheese. 
The acidity in banana-guava cheese variants increased significantly during storage; however, low calorie cheese variant containing stevia had significantly higher acidity as compared to other cheese variants. The increase in acidity of cheese variants might be due to the formation of acidic compounds by degradation or oxidation of reducing sugars, polyphenols and conversion of protein to amino acids by the breakdown of peptide bond. Degradation of polysaccharides, pectic substances and uric acid could also be the reason for the increase in acidity of the products during storage. Similar increase in acidity during storage has been reported by Shabi et al. (2018) ${ }^{[19]}$ in guava cheese and Reddy et al. (2019) ${ }^{[17]}$ in custard apple-apple cheese.

Ascorbic acid content decreased significantly in banana-guava cheese variants during three months storage. The decrease in ascorbic acid of the products could be due to oxidation of ascorbic acid to dehydro-ascorbic acid during storage. Similar finding was also reported by Mehto \& Mehto (2017) ${ }^{[12]}$ in guava cheese. Maximum ascorbic acid was recorded in low calorie cheese variant replacing $25 \%$ sugar with stevia, which might be related to fact that low calorie cheese variant contained more banana-guava pulp per unit weight of the cheese.

The total carotenoids decreased significantly among different banana-guava cheese variants during storage. This might be due to differences in the composition of raw materials among the three recipes. Furthermore, the significant decrease in total carotenoids of the products during storage might be due to thermo-labile, thermo-sensitive and epoxide forming nature of carotene compounds. The results are in conformity with those of Attri et al. (2014) ${ }^{[4]}$ in papaya toffee and Deepika et al. $(2016)^{[7]}$ in aonla based fruit bars.
There was significantly continuous decrease in total phenolic content of banana-guava cheese variants with the increase in storage duration of three months. The decrease in polyphenols during storage might be due to oxidative degradation of phenolic compounds and its condensation into brown pigments. The results of the present investigation are in accordance with the findings of Deepika et al. (2016) ${ }^{[7]}$ in aonla based fruit bars.

The non-enzymatic browning in banana-guava cheese variants increased significantly during storage. The increase in nonenzymatic browning of the products might be due to formation of furfural and hydroxyl furfural by aerobic and anaerobic degradation of ascorbic acid, sugars and organic acids. The results are also confirmed with the findings of Nayak et al. $(2012)^{[14]}$ in aonla candies.

A significant increase in peroxide value of banana-guava cheese variants was observed with the increase in storage period of three months. The reason for increase in peroxide value of cheese variants during storage is due to the fact that phenolic compounds, carotenoids and ascorbic acid content in fruits that helped in improving antioxidant activity and controlling peroxide value of fruit products got decreased during storage. The increase in peroxide value of products during storage was also reported by Khalil et al. (2019) ${ }^{[10]}$ in cheese fortified with pomegranate and lemon peels extract.

The water activity values in banana-guava cheese variants decreased significantly during storage. It might be due to loss of moisture content in the cheese variants. Similar results for decrease in water activity during storage of products were reported by Panwar (2014) ${ }^{[15]}$ in IMF aonla segments during six months storage. Low calorie cheese variant replacing $25 \%$ sugar with stevia had maximum $\mathrm{a}_{\mathrm{w}}$ because stevia did not show binding interaction with water as shown in sugars.

Table 1: Effect of storage on chemical constituents of banana-guava cheese variants

\begin{tabular}{|c|c|c|c|c|c|c|c|c|c|c|}
\hline Treatments* Banana: Guava (40:60) & $\begin{array}{c}\text { Storage } \\
\text { period } \\
\text { (months) }\end{array}$ & $\begin{array}{c}\text { Total } \\
\text { sugars } \\
(\%)\end{array}$ & $\begin{array}{c}\text { Reducing } \\
\text { sugars } \\
(\%)\end{array}$ & (\%) & $\begin{array}{c}\text { Ascorbic } \\
\text { acid } \\
(\mathrm{mg} / 100 \\
\mathrm{g})\end{array}$ & $\begin{array}{c}\text { Total } \\
\text { carotenoids } \\
(\mathrm{mg} / \mathbf{1 0 0} \mathrm{g})\end{array}$ & \begin{tabular}{|c}
$\begin{array}{c}\text { Total } \\
\text { phenols } \\
(\mathrm{mg} / 100 \\
\mathrm{g})\end{array}$ \\
\end{tabular} & \begin{tabular}{|c|} 
Non- \\
enzymatic \\
browning \\
(OD 440)
\end{tabular} & $\left.\begin{array}{c}\text { Peroxide } \\
\text { value } \\
(\text { meq./kg) }\end{array}\right)$ & $\begin{array}{c}\text { Water } \\
\text { activity } \\
\left(\mathbf{a}_{w}\right)\end{array}$ \\
\hline \multirow{4}{*}{ Cheese prepared with sugar } & 0 & 57.30 & 34.80 & 0.80 & 30.96 & 0.52 & 17.63 & 0.219 & 0.13 & 0.75 \\
\hline & 1 & 58.20 & 35.70 & 0.84 & 27.92 & 0.49 & 16.58 & 0.225 & 0.15 & 0.73 \\
\hline & 2 & 58.90 & 36.50 & 0.86 & 24.86 & 0.47 & 15.51 & 0.230 & 0.17 & 0.71 \\
\hline & 3 & 59.70 & 37.20 & 0.89 & 21.80 & 0.45 & 14.45 & 0.242 & 0.20 & 0.70 \\
\hline \multirow{4}{*}{ Cheese prepared by replacing $25 \%$ sugar with stevia } & 0 & 40.80 & 27.20 & 0.98 & 34.54 & 0.48 & 17.65 & 0.182 & 0.22 & 0.73 \\
\hline & 1 & 42.00 & 28.00 & 1.00 & 31.48 & 0.47 & 16.60 & 0.188 & 0.23 & 0.70 \\
\hline & 2 & 43.10 & 28.70 & 1.04 & 29.42 & 0.46 & 15.53 & 0.194 & 0.25 & 0.67 \\
\hline & 3 & 43.80 & 29.50 & 1.07 & 26.38 & 0.44 & 14.47 & 0.204 & 0.27 & 0.65 \\
\hline \multirow{4}{*}{ Cheese prepared by replacing $25 \%$ sugar with jaggery } & 0 & 56.70 & 32.60 & 0.75 & 34.18 & 0.50 & 17.68 & 0.195 & 0.12 & 0.54 \\
\hline & 1 & 57.70 & 33.50 & 0.77 & 31.11 & 0.47 & 16.62 & 0.203 & 0.14 & 0.53 \\
\hline & 2 & 58.60 & 34.30 & 0.81 & 28.00 & 0.45 & 15.54 & 0.208 & 0.15 & 0.52 \\
\hline & 3 & 59.60 & 35.20 & 0.85 & 25.92 & 0.43 & 14.48 & 0.215 & 0.19 & 0.51 \\
\hline \multirow{2}{*}{$\mathrm{CD}$ at $5 \%$} & Treatment & 0.09 & 0.07 & 0.03 & 0.05 & 0.09 & 0.02 & 0.026 & 0.02 & 0.22 \\
\hline & Storage & 0.07 & 0.05 & 0.02 & 0.06 & 0.12 & 0.04 & 0.020 & 0.03 & 0.15 \\
\hline \multicolumn{2}{|l|}{ Treatment x Storage } & 0.17 & 0.13 & NS & 0.10 & 0.22 & 0.13 & 0.400 & NS & 0.40 \\
\hline
\end{tabular}

\section{References}

1. Adamu AS, Ojo IO, Oyetunde JG. Evaluation of nutritional values in ripe, unripe, boiled and roasted plantain (Musa paradisiaca) pulp and peel. European Journal of Basic and Applied Sciences. 2017; 4(1):9-12.

2. Amorium HV, Dougall DK, Sharp WR. The effect of carbohydrate and nitrogen concentrations of phenol synthesis in plant scarlet rose cells grown in tissue culture. Physiologia Plantarum. 1997; 39:91-95.

3. AOAC. Official Methods of Analysis. Association of Official Analytical Chemists, Washington, D.C. $18^{\text {th }}$ edition, 2005.
4. Attri S, Dhiman AK, Kaushal M, Sharma R. Development and storage stability of papaya (Carica papaya L.) toffee and leather. International Journal of Farm Sciences. 2014; 4(3):117-125.

5. Aurore G, Parfait B, Fahrasmane L. Banana raw materials for making processed food products. Trends in Food Science and Technology. 2009; 20:78-91.

6. Brandle J, Telmer P. Steviol glycoside biosynthesis. Phytochemistry. 2007; 68:1855-1863.

7. Deepika, Panja P, Marak DS, Thakur PK. Effect of packaging on quality of enriched fruit bars from aonla (Emblica officinalis G.) during storage. International 
Journal of Agriculture, Environment and Biotechnology. 2016; 9(3):411-419.

8. Hulme AC, Narain R. The ferricyanide method for determination of reducing sugars. A modification of Hagedom-Jensen-Hanes technique. Biochemistry Journal. 1931; 25(4):1051-1061.

9. Kennelly EJ. Sweet and non-sweet constituents of Stevia rebaudiana (Bortoni) Bortoni. In: Stevia, the genus Stevia. Kinghorn AD (ed.), Medicinal and Aromatic Plants-Industrial Profiles. Taylor and Francis, London. 2002; 19:68-85.

10. Khalil MA, Wahed EM, Shalaby HS, Gaballa AS. Production of feta like cheese fortified with pomegranate and lemon peels extract as natural antioxidants. Zagazig Journal of Agricultural Research. 2019; 46(3):711-720.

11. Kumar KS, Bhowmik D, Duraivel S, Umadevi $M$. Traditional and medicinal use of banana. Journal of Pharmacognosy and Phytochemistry. 2012; 1:51-63.

12. Mehto A, Mehto PK. Guava cheese preparation to reduce the perishable loss of fruits and influence of the chemical composition during storage of cheese. International Journal of Food Science and Nutrition. 2017; 2(1):1-3.

13. Nath A, Dutta D, Kumar P, Singh JP. Review on Recent Advances in Value Addition of Jaggery based Products. Journal of Food Processing \& Technology, 2015, 6(440). doi:10.4172/2157-7110.1000440.

14. Nayak P, Tandon DK, Bhatt DK. Study on changes of nutritional and organoleptic quality of flavored candy prepared from aonla (Emblica officinalis G.) during storage. International Journal of Nutrition Metabolism. 2012; 4(7):100-106.

15. Panwar S. Development of Intermediate Moisture Food (IMF) segments and candy from aonla (Phyllanthus emblica L.). Ph.D. Thesis, CCS Haryana Agricultural University, Hisar, India, 2014.

16. Ranganna S. Handbook of Analysis and Quality Control for Fruit and Vegetable Products ( $2^{\text {nd }}$ edition) Tata McGraw Hills Publishing Co. Ltd., New Delhi, 2014.

17. Reddy SK, Bahadur V, Wilson D, Topno SE. Studies on physico-chemical, organoleptic properties and economic analysis of custard apple blended apple cheese. Journal of Pharmacognosy and Phytochemistry. 2019; 8(4):13681372.

18. Rodriguez-Amaya DB. A Guide to Carotenoids Analysis in Foods. ILSI Press, Washington, 2004, 63.

19. Shabi M, Singh D, Prasad VM, Deepansh. Studies on Value Addition of Guava Cheese. The Allahabad Farmer, 2018, 74(1).

20. Singh K, Mishra S, Prasad VM. Effect of different ratio of pineapple and apple pulp on quality and shelf life of blended cheese. International Journal of Chemical Studies. 2017; 5(4):1212-1216.

21. Starrat AN, Kirby CW, Pocs R, Brandle JE. Rebaudioside F- a diterpene glycoside from Stevia rebaudiana. Phytochemistry. 2002; 59:367-370. 